\title{
Vivir y pensar la construcción de la sociedad anarquista desde la realidad mesoamericana, ayer y hoy*
}

\section{Living and thinking about the construction of anarchist society from the Mesoamerican reality, yesterday and today}

\author{
Benjamín Maldonado Alvarado \\ Programa de Posgrado de Pedagogía \\ Universidad Nacional Autónoma de México \\ En recuerdo
de Omar Cortés y Chantal López
}

\section{Resumen}

La vida comunal de los pueblos mesoamericanos ha sido la base de la resistencia indígena comunitaria frente al colonialismo español y luego frente al mexicano. Este modo de vida y de pensar fue considerado por los magonistas, en la década de 1910, como la poderosa experiencia histórica que sería la base para la reconstrucción libre de la sociedad mexicana, después del triunfo de la corriente anarquista de la revolución que impulsaban desde el exilio en Estados Unidos; pero no valoraron a la comunalidad como una forma de resistencia para liberarse del colonialismo capitalista, porque suponían muerto un modo de vida que hoy sigue vivo en comunidades de estados como Oaxaca.

\section{Palabras clave:}

Comunalidad, resistencia indígena, colonialismo, magonismo anarquista.

\section{Abstract}

The communal life of the Mesoamerican communities has been the historical basis of indigenous resistance against Spanish colonialism and then against Mexican colonialism. This way of life and mentality was considered by the magonistas in the 1910s as the powerful historical experience that would be the basis for the free reconstruction of society after the triumph of the anarchist sector in the Mexican revolution that they organized in exile from the United States. But they did not value communality as a form of resistance to achieve the liberation of capitalist colonialism, because they supposed dead a way of life that is still alive today in communities of places like Oaxaca.

\section{Key words:}

Communality, indigenous resistance, colonialism, anarchist magonism.

\footnotetext{
* Este trabajo emana de una obra anterior del autor: Ante el centenario de la Revolución Mexicana: magonismo y vida comunal mesoamericana. Ver ficha completa en Referencias.
}

Recibido: 20 de septiembre de 2019 


\section{Introducción}

Una de las características actuales del sur en México es lo mesoamericano. El horizonte civilizatorio mesoamericano, que comparten los pueblos del centro y sur del país y parte de Centroamérica, según las cartografías arqueológica y antropológica, contrasta con un horizonte "desorientado", que se puede llamar occidental y del norte. En una relación de completa y agresiva desigualdad, en México, el horizonte occidental se ha impuesto al mesoamericano, estableciendo dicha relación colonial en términos de dominación y resistencia desde el surgimiento de la modernidad, hace más de cinco siglos.

En su etapa virreinal de tres siglos, la dominación colonial de las comunidades mesoamericanas fue resistida con la fuerza suficiente de los indígenas, que les permitió sobreponerse a la muerte de la mayoría de su población, ocurrida en el llamado siglo de la depresión (Borah, 1982), además, cumplir con el pago oneroso de los tributos a los españoles y recuperar su dinámica demográfica, sin perder su cultura y su lengua, aunque esto último sí ocurrió en varios casos; sin embargo, el colonialismo mexicano fue más agresivo, pues, empobrecidos con el desarrollo del capitalismo, el consecuente despojo de tierras y la reconversión productiva, tuvieron que enfrentar el colonialismo interno (González-Casanova, 2006) y la agudización del etnocidio.
En Oaxaca, la resistencia comunitaria a las dominaciones colonial española y mexicana tiene su base en una forma de organización social de larga duración, que muestra importantes características cercanas a un tipo de sociedad anarquista y se le llama vida comunal o comunalidad; por tanto, es necesario analizar desde otra perspectiva, el anarquismo en dicha entidad, porque está basado en una práctica histórica, que es la vida comunal en las comunidades mesoamericanas, relacionada con planteamientos anarquistas internacionales, en especial con las ideas de Kropotkin (1902), expuestas en su monumental libro, El apoyo mutuo.

\section{Vida comunal y magonismo ayer}

Hace más de cien años, Ricardo Flores Magón impulsaba una revolución anarquista en México, ${ }^{1}$ y en 1911, en plena agitación, definía la anarquía como el "orden basado en el apoyo mutuo"; ${ }^{2}$ buscaba la construcción de una sociedad anarquista sobre las ruinas de la sociedad capitalista, a la que había que destruir y definía como el desorden sostenido por el Estado, el clero y el capital para beneficio del burgués. ${ }^{3}$

Las ideas fundamentales de Flores Magón eran luchar por Tierra y Libertad, para acabar con el desorden establecido a partir de la expropiación de la riqueza y de los medios de producción, ${ }^{4}$ los cuales habían sido arrebatados por

\footnotetext{
I "Somos antiautoritarios, esto es, anarquistas... Por lo demás, todos los anarquistas estamos convencidos de que el derecho de propiedad individual es la causa de la esclavitud económica, política y social del proletariado” (Flores Magón, 1982, p. 69).

2 "Los que esperaban que esta Revolución sería una revuelta de ópera bufa que terminaría con el encumbramiento de un nuevo tirano, están ahora espantados. La anarquía reina en México, dicen esos pobres de espíritu, sin saber que la anarquía es orden basado en el apoyo mutuo” (Flores Magón, I980, p. 96). 3 "Los funcionarios públicos no son, como se cree, los guardianes del orden. El orden, que es la armonía, no necesita guardianes, precisamente porque es orden. Lo que sí necesita guardianes es el desorden, y desorden escandaloso, vergonzoso y humillante para los que no nacimos para esclavos, es el que reina en la vida política y social de la humanidad...

Para mantener el desorden, esto es, para mantener la desigualdad política y social, para mantener los privilegios de la clase alta y tener sometida a la clase baja, es para lo que se necesitan los gobiernos, las leyes, los polizontes, los soldados, los carceleros, los jueces, los verdugos y toda una caterva de altos y pequeños funcionarios que chupan las energías de los pueblos de la Tierra. No es para proteger a la humanidad para lo que existen esos funcionarios, sino para tenerla sometida, para tenerla esclavizada en beneficio de los que se han dado maña para retener hasta hoy la tierra y la maquinaria...

$\mathrm{Al}$ orden burgués, los mexicanos contestamos con nuestra rebeldía. Contra ese orden gritamos: ¡muera el orden! Porque es un orden que maniata la libre iniciativa del ser humano, porque es un orden de cuartel o de presidio. ¡Muera el orden!” (Flores Magón, 1980, pp. 87-88).

4 "Armáos, compañeros. Armáos, hermanos de miseria y de cadena. No os declaréis más en huelga: tomad posesión de la fábrica, del taller, de la mina, del campo. Desconoced resueltamente el derecho de propiedad que es un derecho inicuo que condena a una parte de la humanidad, a la gran mayoría de la humanidad, a estar sujeta a la voluntad de los ricos.

Declarad guerra a muerte a los ricos, y tomad todo lo que ellos poseen para que, de hoy en adelante, tierras, minas, fábricas y talleres sirvan para el uso y disfrute de todos, hombres y mujeres. De ese modo conquistaréis vuestra emancipación económica que es la base de todas las libertades. Los ricos son libres precisamente porque no dependen económicamente de nadie.

No abandonéis el lugar de trabajo ni os crucéis de brazos, tomad posesión de la mina, del taller, de la fábrica, del campo; trabajad bajo un pie de igualdad y estableced un sistema de intercambio de productos. Fúndense almacenes en que se depositen los productos de toda clase y a los cuales tengan acceso todos aquellos que hayan contribuido con su trabajo a la producción, para que tomen de ellos lo que necesiten” (Flores Magón, 1980, pp. 117-118).
} 
los burgueses a los pobres del campo y la ciudad, así como terminar con los poderes del Estado, de los capitalistas y del clero en cada población, mediante las armas. ${ }^{5}$ A esto seguirían de inmediato la distribución de la riqueza, la administración colectiva de los bienes, la puesta en marcha del sistema productivo, con base en la organización colectiva de los trabajadores de cada rama, y la defensa de lo conquistado mediante las armas. ${ }^{6}$

Aconsejad a los peones que trabajen las haciendas por su cuenta; a los mineros decid que extraigan los metales y el carbón también por su cuenta; a los obreros de las fábricas invitadlos a que hagan lo mismo, y así sucesivamente. Aconsejad que se formen grandes almacenes con lo que produzcan los trabajadores, para que todos los que hayan contribuido a la producción, tengan derecho de tomar todo lo que necesiten (Flores Magón, 1980, p. 146).

La estrategia de lucha mostraba el sentido de una revolución completa, de raíz, y no sólo un cambio en el poder:

En la insurrección armada, como la entendía el magonismo, la espontaneidad de las masas debería jugar un papel importante. Politizado por largos años de propaganda y sometido a una situación política y económica insostenible, el pueblo, a pesar de no estar organizado, respondería, espontáneamente, ${ }^{7}$ lanzándose a la lucha si una serie de grupos suficientemente numerosos y más o menos estructurados se levantaban simultáneamente en armas y lograban sobrevivir por un cierto tiempo. Estas guerrillas deberían tomar por sorpresa poblaciones pequeñas y medianas y en cada lugar establecer el poder del pueblo y darle materialidad, sobre la marcha, a las principales reivindicaciones del Programa Liberal. A partir de estas zonas liberadas, la insurrección debería extenderse multiplicando sus fuerzas y recursos a costa del enemigo (Bartra, 1977, p. 25).

Según los magonistas, en el México de 1911, la conformación anarquista de un mundo nuevo era posible, por tres razones fundamentales:

1) El pueblo mexicano estaba harto de la explotación y despojo capitalistas que los habían sumido en la pobreza y el atraso.
2) El Partido Liberal Mexicano desarrollaba una importante actividad de agitación concientizadora y la gente se organizaba en grupos guerrilleros que apoyarían los actos de expropiación realizados en poblaciones concientizadas. ${ }^{8}$

3) Una vez destruido el desorden establecido, era posible reorganizar la sociedad, por la experiencia histórica "casi comunista" que habían vivido la mayoría de los mexicanos, fundada en la organización de las comunidades indígenas.

Esto último era algo realmente novedoso, encontrar un valor positivo en la forma de organización de los pueblos indígenas, a principios del siglo XX; además, el argumento mostraba un conocimiento importante de la realidad indígena, por ejemplo, en el siguiente texto:

Pocos serán ya los que ignoren que el movimiento revolucionario iniciado por el Partido Liberal Mexicano en septiembre de 1906, y que continúa en pie, es un movimiento de carácter económico, que cada vez va siendo mejor orientado hacia una finalidad precisa: el comunismo.

He dicho más de una vez, que la vida de las poblaciones rurales hasta hace pocos lustros, en México, era casi comunista. El apoyo mutuo era la regla entre los sencillos habitantes cuyas casas eran construidas por los vecinos del pueblo; las cosechas eran levantadas por todos; las escardas y otros trabajos en que se requería un mayor número de brazos que los de una familia, se practicaban en común; de uso común eran las tierras destinadas a la cría de los animales útiles; como de común uso eran las aguas del torrente, de la fuente, del lago, $y$, de explotación común el bosque cercano, la cantera de tepetate o de tezontle, el malpaisal para elaborar los metates y los molcajetes, los yacimientos de cal, de sal, etc., etc. La moneda no era necesaria para las transacciones de cada comunidad. El intercambio de productos y de materias primas era la regla, y solamente se necesitaba el dinero para llevar de la ciudad más o menos cercana lo que en el lugar no se producía, y casi siempre se obtenía ese dinero, llevando a la ciudad legumbres, materia prima, ganado, sal, cal, etc.; pero era bien poco lo que necesitaba en monedas, porque la pequeña industria de cada lugar producía casi todo lo necesario para el consumo de la comunidad. Apenas si se hacía sentir

\footnotetext{
${ }^{5}$ Ver por ejemplo el cuento "Expropiación” (Flores Magón, 1981a, pp. 69-72).

${ }^{6}$ En algunos de sus cuentos Ricardo Flores Magón hace una extensa descripción de cómo imagina la reorganización de la vida después del triunfo de la revolución, en especial en las ciudades, por ejemplo, en "Vida Nueva" (Flores Magón, 1981a, pp. 141-150).

${ }^{7}$ En esto, Flores Magón sigue en especial a Enrico Malatesta, cuya frase "La masa se volverá anarquista y comunista durante la revolución, después del comienzo de la revolución, no antes" citaría en "El deber del revolucionario" (Flores Magón, 1982, p. 65), para afirmar: "Hacemos nuestra la opinión de Malatesta. Además, los miembros del Partido Liberal Mexicano no nos conformamos con esperar a que comenzara la Revolución mexicana, sino que la forzamos, la precipitamos, para tener la oportunidad de encauzarla con la acción y con la palabra hacia el comunismo anárquico".

8 "No esperéis a que pase por el lugar de vuestra residencia alguna guerrilla de los nuestros. Poneos de acuerdo varios e ingresad a la primera fuerza que pase o que sepáis que se encuentra cerca, cualquiera que ella sea. En seguida, ya sabéis lo que tenéis que hacer: aprovechar la primera oportunidad para separaros a luchar por nuestros caros ideales, llevándoos con vosotros a todos aquellos que habráis convertido en conscientes" (Flores Magón, 1981, p. 36); se refiere a las fuerzas maderistas o vazquistas, la sugerencia era infiltrarse para obtener armas y luego salirse. Una amplia y documentada exposición de la organización del PLM se puede ver en López y Cortés (1986).
} 
la Autoridad, la cual ha sido siempre odiada cordialmente por el pueblo mexicano (Flores Magón, 1981, p. 24).

En esta visión, el aporte principal consiste en reconocer la tradición organizativa comunal, de apoyo mutuo, de orden colectivo, que permitiría a las poblaciones liberadas del país reorganizar su vida y crear una sociedad con un orden fundado en el apoyo mutuo. En otras palabras, reconstruir el país, reorganizar la sociedad, reorientar la vida lejos del desorden empobrecedor, sería posible recurriendo a una experiencia histórica a la que consideraban recién muerta.

Sin nombrar a la comunalidad, Ricardo y Enrique Flores Magón otorgaban un alto valor a aspectos fundamentales de las sociedades comunales, a las que sentían su pertenencia le daba sentido a su lucha. ${ }^{9}$ Por aquel tiempo, la anarquista estadounidense, Voltairine de Cleyre, destacaba el carácter comunal en la Revolución mexicana (La Botz, 2014), en un sentido muy similar al de Flores Magón:

\begin{abstract}
Las costumbres comunistas de estos pueblos son muy interesantes, y muy aleccionadoras también; y las han estado practicando durante cientos de ańos, a pesar de la civilización extranjera que estaba siendo injertada en México (injertada en todos los sentidos de la palabra); y no fue sino hasta hace cuarenta años (de hecho, lo peor de todo no tiene más de veinticinco años), que el creciente poder del gobierno hizo posible destruir su antiguo modo de vida... Entre ellos tienen en común los bosques, las aguas y las tierras. Cualquiera puede cortar del bosque la madera que necesite para construir su cabaña, y puede hacer uso de los ríos para regar su campo o su pedazo de jardín (y este es un derecho cuyo reconocimiento ninguno puede apreciar plenamente su imperiosa necesidad mejor que los que conocen la aridez del suroeste). Las tierras cultivables eran asignadas por mutuo acuerdo antes de la siembra, y volvían a la tribu después de la cosecha, para su reasignación. Los pastos y el derecho a recolectar combustible, eran para todos. Los hábitos de ayuda mutua que siempre surgen en las comunidades poco pobladas eran instintivos entre ellos. Un vecino era ayudado por otros vecinos para construir su cabaña, para arar su tierra, para recoger su cultivo y almacenarlo (De Cleyre, 1914, pp. 257-258).
\end{abstract}

No es claro si fue ella quien ejerció una influencia analítica notoria en Flores Magón o viceversa, pero aportó ideas importantes al análisis de la presencia de lo indígena en la Revolución mexicana:
En la tribu yaqui, Voltairine de Cleyre subraya todos los elementos que, a su juicio, hicieron de la población indígena el elemento impulsor de la resistencia a la expansión capitalista... A los ojos de la conferencista, el propósito del régimen porfirista de "civilizar México" provocó una inmisericorde desorganización de la vida indígena, a la que contribuyeron las concesiones "civilizatorias" a capitalistas extranjeros y nacionales (Torres, 1990, p. 161).

El carácter anarquista de la propuesta magonista se percibe tanto en la forma de acabar con el desorden establecido -mediante la expropiación y la destrucción de los poderes del Estado, de la burguesía y del clero-, como en la manera de construir un orden nuevo, contando con la disposición basada en la experiencia comunal de la mayoría.

Sin embargo, aun cuando el magonismo reconoce el valor de la vivencia comunal para la generación de un mundo nuevo, no se trata de un reconocimiento sostenido ni la comunalidad tiene un lugar importante, ni permanente, en su labor de agitación y concientización, es decir, en los argumentos de la lucha revolucionaria de los magonistas; sólo se menciona algunas veces, en menos de diez textos, de los cientos que escribió Ricardo Flores Magón; por ejemplo, no se encuentra en el documento más importante de la época anarquista, que es el Manifiesto del 23 de septiembre de 1911, como tampoco en la carta de 1908, de Ricardo Flores Magón a sus hermanos Enrique y Jesús, y a Práxedis Guerrero.

¿Qué pasó?, ¿por qué se percibe con claridad un alto aprecio a la comunalidad, pero no constituye un eje importante en el discurso revolucionario del movimiento magonista? Al parecer, la invisibilizó el peso de la mirada socialista y positivista y, con ello, se dejó de percibir y valorar su rol fundamental en la resistencia contra el capitalismo desde las comunidades.

\section{La vida comunal estaba muerta}

$\mathrm{Al}$ igual que los revolucionarios de finales del siglo XIX, los magonistas daban por hecho que la vida comunal había desaparecido.

\footnotetext{
${ }^{9}$ Como ejemplo, en una carta del 8 de marzo de 1921, Ricardo Flores Magón escribió a Ellen White desde la cárcel: "Soy un salvaje, un hijo de la naturaleza. Por eso siento cualquier ataque dirigido a mi libertad. Mi alma está animada todavía por el palpitar de las montańas que me vieron nacer, un latido vigoroso, un latido puro" (Flores Magón, 1976, p. 114). Su hermano Enrique diría durante un juicio en 1916: "Ricardo y yo somos indios, proletarios. Nacidos y crecidos entre los pobres, somos testigos de las grandes injusticias, de la tiranía y de la explotación que han sufrido las masas. Por eso somos anarquistas comunistas" (Kaplan, 2006, p. 435).
} 
Estas sencillas costumbres duraron hasta que, fuerte la autoridad por la pacificación completa del país, pudo garantizar a la burguesía la prosperidad de sus negocios. Los generales de las revueltas políticas recibieron grandes extensiones de terrenos; los hacendados ensancharon los límites de sus feudos; los más viles politicastros obtenían como baldíos terrenos inmensos, y los aventureros extranjeros obtuvieron concesiones de tierras, bosques, aguas, de todo, en fin, quedando nuestros hermanos indios sin un palmo de tierra, sin derecho a tomar del bosque ni la más pequeña rama de un árbol, en la miseria más abyecta, despojados de todo lo que era de ellos (Flores Magón, 1980, p. 171).

Había sido destruida por el proceso de despojo con que se realizó la acumulación originaria de capital, es decir, cuando el porfirismo sentó las bases del desarrollo capitalista, desposeyendo con violencia a los campesinos de sus medios de producción y proletarizándolos:

Pero llegó la hora del desarrollo industrial de México; grandes fábricas y talleres fueron establecidos; los hacendados, tentados por la codicia, comenzaron a robar las tierras de los pueblos, y entonces los que cultivaban para ellos mismos la tierra, tuvieron que cultivarla para los hacendados, y los que quisieron librarse de esa servidumbre, encontraron trabajo en las flamantes negociaciones de las ciudades, ganando salarios de hambre, sufriendo humillaciones mil, o emigraron hacia los centros mineros o al extranjero.

Un profundo malestar económico fue acentuándose entre el proletariado, y esto, unido a la tiranía política, tuvo como resultado la Revolución (Flores Magón, 1981, pp. 24-25).

Esta perspectiva muestra que el punto de observación de la realidad no era el propio, es decir, la realidad rural se miraba desde la urbana; y las condiciones de vida de los trabajadores en la ciudad (en su mayoría migrantes, ex campesinos), y su agresivo empobrecimiento y sometimiento político, mostraban una realidad brutal contra la que había que luchar:

Haciendo concesiones aquí y allá y en todas partes de México, más de 20 millones de acres fueron dados por Díaz a capitalistas de Estados Unidos sólo, por no mencionar lo que entregó a los de otros países.

Toda esa tierra le fue quitada al pueblo mexicano por la fuerza. Cuando el pueblo objetaba contra este despojo que sufría su propiedad, lo asesinaban en masa, o individualmente, en las carreteras, en las calles y aún en sus casas, los soldados de Porfirio Díaz...

Después de que mi pueblo fue despojado de todas sus posesiones, se convirtió en esclavo, en paria; no tenía ni un terrón de lo que había sido suyo una vez... Quedaron reducidos al triste estado de peones (Kaplan, 2006, p. 434).

Tal vez resulte exagerado sostener una afirmación tan absoluta, pero refleja la realidad que había que denunciar y combatir; así, desde la realidad de los derrotados, era difícil de percibir a quienes resistían, desde las comunidades, a la expansión depredadora del capitalismo, organizados en una forma de vida comunal a la que se había dado por muerta de forma prematura. ${ }^{10}$

\section{El deslumbramiento del progreso}

El magonismo también seguía a los revolucionarios de su época y otorgaba un valor muy alto a la ciencia y al progreso; centraba su interés en las formas de extender los grandes beneficios de la civilización a los pobres, a los desposeídos, lo cual se haría mediante la expropiación y la extensión del bienestar social.

Uno de los anarquistas que más cita Flores Magón es el connotado científico, Kropotkin, en particular, su libro La conquista del pan; la obra abunda en ideas acerca de los logros de la ciencia y las formas en que el progreso puede alcanzar a las mayorías, reduciendo las horas de trabajo y mejorando la producción. El punto desde donde ve la realidad es claro:

Somos ricos en las sociedades civilizadas. ¿̨or qué hay, pues, esa miseria en torno nuestro?... Porque todo lo necesario para la producción ha sido acaparado por algunos en esta larga historia de saqueos, guerras, ignorancia y opresión en que ha vivido la humanidad... Porque se apropian hoy dos tercios del producto del trabajo humano, dilapidándolos del modo más insensato y escandaloso... Porque le impiden (a las masas) producir lo que necesita y le fuerzan a producir, no lo necesario para los demás, sino lo que más grande beneficio promete al acaparador (Kropotkin, 1971, p. 13).

Desde esa época, todas las sociedades deben aspirar al beneficio del progreso, como una especie de derecho universal por el cual habría que luchar. La conquista del pan o la reconquista de lo humano pasaría necesariamente por la apropiación de los satisfactores de los civilizados. En ese contexto, las sociedades comunales ajenas a la civilización occidental tendrían que dejar de serlo, para occidentalizarse. En un razonamiento así, lo comunal no sería un

\footnotetext{
${ }^{10}$ También desde la antropología se daba por fenecida la comunalidad y, con ella, la resistencia. Uno de los antropólogos indigenistas más importantes, Gonzalo Aguirre Beltrán, al referirse al relato de lo comunal que Enrique Flores Magón escuchó de su padre, dice: "El conocimiento más cercano a la verdad que la etnografía moderna suministra de la vida en las comunidades indígenas difiere en gran medida de la visión mítica que de ella nos da el pensamiento romántico del siglo decimonono; en el cuadro que pinta Teodoro Flores y que internaliza en el subconsciente de sus hijos, hay algo de cierto y mucho de fantasía" (Aguirre, 1980, p. IX).
} 
valor, sino más bien un obstáculo; sin embargo, no era un problema real, porque ya se había dado por muerta.

La lucha por los beneficios del progreso queda clara en textos como el fundamental Manifiesto del 23 de septiembre de 1911:

Mexicanos: el Partido Liberal Mexicano reconoce que todo ser humano, por el solo hecho de venir a la vida, tiene derecho a gozar de todas y cada una de las ventajas que la civilización moderna ofrece, porque esas ventajas son producto del esfuerzo y del sacrificio de la clase trabajadora de todos los tiempos" (Flores Magón, 1981, p. 169).

En contraste directo, las carencias derivadas del despojo y de la falta de acceso a los beneficios modernos aparecían de forma automática e incuestionable, como un objetivo legítimo de lucha, pero desde la mirada socialista, positivista, urbana.

\section{La resistencia ya no existía}

Estos ideólogos sí reconocían la vida comunal, pero estaban seguros de que el capitalismo la había derrotado, de dos a cuatro décadas antes de 1911, y la resistencia habría muerto con ella. Más aún, la vida comunal feneció al ser vencida la resistencia y los ex comuneros desposeídos se transformaron en peones o proletarios. Para estos revolucionarios, la organización "casi comunista", tan apreciada, se había extinguido el siglo anterior y, aunque se podía recurrir a ella para forjar una sociedad anarquista, no había forma de percibir la resistencia y mucho menos de valorarla; sólo se hacía referencia a su existencia histórica, lo cual ya era un gran aporte del magonismo, sin embargo, se quedaba corto.

En cambio, Voltairine de Cleyre habló de la resistencia indígena al capitalismo, desde la vida comunal, y visualizó que la expansión porfirista de la civilización occidental destruía intencionalmente la vida comunal y, con ella, la resistencia. De modo que incluso ella daba por muerta la resistencia y la comunalidad, aunque reconoció el valor revolucionario en aquélla, como ningún otro contemporáneo lo hizo. ${ }^{11}$

Los magonistas veían la vida comunal aplastada por el capitalismo, y tan agredida, que la situación era insoportable, por lo que era necesario iniciar la revolución.
En ese proceso, la mayoría de la población estaba cada vez más lejos de acceder al progreso, a la "civilización", concebidos como los máximos logros de la humanidad y de los que todos deberían disfrutar. Las comunidades rurales eran náufragas y sin recursos civilizatorios. Desde esa perspectiva, aunque la vida comunal podía ser revivida para reconstruir la sociedad al triunfo de la revolución, tendría que ponerse en sintonía con la modernidad para ser efectiva.

\section{Resistencia y vida comunal hoy}

En suma, el panorama que observaban críticamente los magonistas era el de una sociedad comunal derrotada, despojada, desorganizada, en la que sus miembros eran absorbidos por el individualismo, propio de Occidente, y por el empobrecimiento radical, propio del desarrollo capitalista; lucharían para que los desposeídos tomaran posesión de los bienes y los medios de producción, acabando con el poder económico, político y religioso en que se sustentaba el despojo.

Hoy en día, la comunalidad sigue viva y desde ella resisten los pueblos mesoamericanos; ambas, resistencia y comunalidad, percibidas como muertas-vivas y de alguna manera invisibilizadas, continúan vigentes en muchas comunidades indígenas y les han permitido enfrentar al capitalismo, al colonialismo y al etnocidio, y seguir existiendo luego de casi un siglo de agresiones crecientes a su territorio, a su economía, a su organización, a su identidad, a su lengua y cultura.

La agresión colonial se intensificó desde la constitución del Estado mexicano, sobre todo a partir del porfiriato, en la segunda mitad del siglo XIX, en lo que se ha llamado el colonialismo interno. Esa agresión adquirió el carácter etnocida, cuando el Estado mexicano declaró la guerra a las culturas indígenas, desde la década de 1920, y acentuó la agresión cincuenta años después. El contexto de esta violencia es el capitalismo en sus distintas fases de desarrollo, desde la acumulación originaria del porfiriato, hasta el neoextractivismo actual.

La evidente y documentada existencia de vida comunal en las comunidades de todo Oaxaca, hablantes o no de lenguas indígenas, revela el fuerte carácter de resistencia

\footnotetext{
${ }^{11}$ Es interesante notar que, en La conquista del pan, Kropotkin no hace referencias a la ayuda mutua, cuya importancia histórica documentó con gran amplitud. El hecho de que haya escrito El apoyo mutuo como factor de evolución, diez años después del primero, no parece ser razón suficiente; aunque, sin duda, Ricardo Flores Magón leyó ambos.
} 
con que se ha vivido la comunalidad; la etnografía las muestra vivas, florecientes y contradictorias, resultantes de una experiencia humana conflictuada, atravesada por siglos de colonialismo y décadas de brutal etnocidio, que inevitablemente dejan huella; tienen la imperfección de la utopía realizable, pero existen.

La fuerza social de la resistencia que se asienta en sociedades estructuradas y fincadas en el apoyo mutuo, que intentan generar orden en su interior y solucionar los conflictos con base en esos recursos de la comunalidad, hacen ver en ellas una lógica plenamente compatible con las aspiraciones anarquistas, siguiendo la definición magonista de anarquía como orden basado en el apoyo mutuo.

Las comunidades mesoamericanas en Oaxaca tienen la estructura necesaria en su vida comunal para funcionar de forma adecuada, lo cual logran o pierden coyunturalmente, pero que es la base para buscarlo. Eso recuerda que para Ricardo Flores Magón el orden buscado es armonía, ${ }^{12}$ pero no una avenencia idílica y por tanto irreal, sino construida en sociedad, fundada en la participación colectiva en los asuntos de la comunidad, tratando de generar relaciones armónicas e igualitarias en sociedades que siempre son conflictivas y desiguales.

La sociedad anarquista sigue siendo un objetivo por lograr; pero hoy, se podría definir la anarquía en Oaxaca, como un orden basado en el apoyo mutuo frente al desorden capitalista colonial; no se trata de un orden que se deba construir una vez derrotado el sistema totalitario que nos rige, sino del que ha sido la base para resistir frente al desorden, para mantener una fuerza organizativa cimentada en la cultura originaria, con la que se ha resistido al desorden establecido. La comunalidad es el orden basado en el apoyo mutuo; es orden local, organización que no se hace descomunal y se sale de las manos de la gente, sino que puede continuar bajo el control de la asamblea; es apoyo mutuo con gusto, festivo, es costumbre que se celebra.

En Oaxaca, no se necesita construir algo nuevo, sino destruir algo impuesto, transformarlo en algo positivo; es decir, mantener el orden comunal, extenderlo, fortalecerlo y luchar por acabar con el desorden colonial capitalista.
Según una de las propuestas del movimiento indígena, extender el orden comunal significa la reconstitución de pueblos, esto es, la promoción de asambleas panétnicas que incluyan a todas las comunidades de cada pueblo indígena (en específico, a sus asambleas), pero también la conformación de asambleas regionales de comunidades no sólo indígenas y de espacios urbanos de empoderamiento, mediante asambleas territoriales (colonias, barrios, cuadras), con diversas temáticas (de género, de trabajadores, estudiantiles, entre otras). ${ }^{13}$

Tal vez la opción sea construir esos espacios de emancipación para ir socavando al Estado, disminuyéndolo, hasta tomar en manos confederadas las funciones de coordinación regional y nacional, al menos mientras se discute la conveniencia o no de la figura organizativa nacional.

Hoy en día, la lucha contra el poder capitalista es la lucha contra el narco-Estado nacional, de modo que la destrucción del desorden imperante pasa necesariamente por el fin del capitalismo, del colonialismo etnocida y del Estado; uno de los ámbitos más potentes para enfrentarlos es la vida comunal mesoamericana, desde una perspectiva anarquista que engloba el orden basado en el apoyo mutuo y la autogestión cimentada en la comunalidad y la soberanía alimentaria; no se debe olvidar que esa forma de vida tiene su centro y sentido profundo en la milpa (Rendón, 2011) para las comunidades rurales.

\section{Ayer y hoy}

Es importante considerar algunas diferencias entre el ayer y el hoy en el orden basado en el apoyo mutuo, como se percibe en Oaxaca, y sus posibilidades constructivas, entre otras las siguientes: ${ }^{14}$

1. La resistencia comunitaria ha mostrado la fortaleza de la vida comunal, pues la agresión etnocida del Estado mexicano se intensificó al máximo a partir de la década de 1920, después de la llamada Revolución y de la muerte de Ricardo Flores Magón.

2. Cada vez son más los adultos y jóvenes que piensan críticamente en su realidad y en el proceso de

\footnotetext{
12 “¡Ah, el orden! Así gimen en estos momentos, todos los partidarios de lo que se llama orden. El orden, para esas pobres gentes, sólo puede subsistir estando la humanidad sometida a la férula del polizonte, del soldado, del juez, del carcelero, del verdugo y del gobernante. Pero eso no es el orden. Yo entiendo por orden: armonía, y la armonía no puede ni debe existir mientras haya sobre la superficie del planeta seres humanos que tienen qué comer en abundancia, y seres humanos que no tienen un pedazo de pan que llevarse a la boca” (Flores Magón, 1980, p. 87).

${ }^{13}$ Zibechi (2008) los llama espacios de emancipación y documenta diversos ejemplos en el continente.

${ }^{14}$ Hay que decir que hoy, como en su momento lo hizo Aguirre Beltrán, muchos académicos aseguran que lo "indio" es una invención de antropólogos; que la vida comunal es sinónimo de sociedad idílica y, por tanto, es irreal; que la idea de comunalidad es esencialista y, por tanto, cuestionable; que la comunidad
} 
fortalecimiento de su identidad; tras varias décadas de avergonzamiento, muestra una dinámica cercana al momento en que la resistencia cumpla su objetivo social, que es dar paso a la liberación, después de haber incubado lo propio.

3. A diferencia de la época magonista, en que lo comunal apenas se percibía, hoy se cuenta con décadas de formulación y conformación de una idea sistemática: la comunalidad, de la que se apropian distintos actores sociales.

4. El individualismo se ha desarrollado, trayendo desgaste y desorientación a la vida comunitaria y ha debilitado la resistencia.

5. El progreso muestra hoy su falacia, sus graves consecuencias y sus contradicciones, más allá de sus beneficios; estos últimos son contrastados con la capacidad autogestiva de lo comunitario; por su parte, los intelectuales y académicos locales se están apropiando de los beneficios de la ciencia y la tecnología a diversos ritmos.

6. La perspectiva socialista, que mostraba un capitalismo depredador en expansión incontrolable, cede ante la perspectiva de espacios de resistencia a la depredación.

7. Esa misma perspectiva, que no encontraba valor en lo indígena o comunal -salvo en casos como el magonismo, o pensadores como Mariátegui, y de alguna manera Chayanov-, ha tenido que reconocer el carácter positivo de la resistencia anticapitalista desde lo comunal.

8. Hoy, la comunalidad cuenta con diversos teóricos anarquistas, además de Kropotkin, para argumentar sus razonamientos e intenciones, como Murray Bookchin, en especial sus tesis sobre municipalismo libertario, y Pierre Clastres, en su caracterización del Estado monológico y los intentos por evitarlo.
Las comunidades mesoamericanas y los ámbitos en los que se construye la vida comunal son espacios donde el orden basado en el apoyo mutuo define la vida y su forma de comprenderla. Estos espacios serán parte de sociedades comunistas ácratas, cuando desde ellos, y mediante diversas formas de lucha y acción, se derrote el desorden sustentado por el narco-Estado, el capitalismo y el colonialismo, sustituyéndolos por confederaciones de base, producción (incluso de alta tecnología) controlada por las personas y las relaciones interculturales.

\section{Referencias*}

Aguirre, B. G. (1970). Introducción. Ricardo Flores Magón. Antología. México: UNAM.

Bartra, A. (1977). Regeneración 1900-1918. México: Era.

Borah, W. (Coord.). (2002). El gobierno provincial en la Nueva España, 1570-1787. México: Instituto de Investigaciones Históricas-UNAM. Recuperado de la publicación en línea (2018), en www.historicas.unam.mx/publicaciones/ publicadigital/libros/215/gobierno provincial.html

Boron, A. A., Amadeo, J., González, S. (Comps.). (2006). Colonialismo interno (una redefinición). La teoría marxista hoy. Problemas y perspectivas. Buenos Aires: CLACSO. Recuperado de http://bibliotecavirtual.clacso.org.ar/ar/ libros/campus/marxis/marxis.html

De Cleyre, V. (1914). The Mexican Revolution. En: Alexander Berkman (Ed.), Selected Works of Voltairine de Cleyre. New York: Mother Earth Publishing Association.

Flores, M. R. (1976). Su vida, su obra (con un estudio de B. Cano Ruiz) y 42 cartas en facsimil escritas en inglés durante los dos últimos años de su prisión y de su vida (traducidas al castellano por Proudhon Carbó). México: Editores Mexicanos Unidos.

está llena de conflictos y es presa fácil de la manipulación, llegando a poner sus tradiciones al servicio de la dominación y la violación de derechos humanos; es decir, que lo evidente debe ser puesto en duda y visto desde una realidad ajena, en aras de lograr rigor académico frente a una teoría que, en el mejor de los casos, se considera una mirada empirista, no científica. Obviamente, la descalificación de la comunalidad implica de inmediato la denostación o el menosprecio por la resistencia; para ese sector de la academia, el orden basado en el apoyo mutuo se hundió hace tiempo o naufraga miserablemente.

* Para una consulta óptima, se sugiere al lector que copie y pegue el vínculo en el motor de búsqueda de su preferencia. 
Ediciones Antorcha.

(1980). Artículos Politicos 1911. México:

(1980a). La paz. Regeneración, 3 de junio de 1911, 96.

(1980b). ¡Muera el orden! Regeneración, 13 de mayo de 1911, 87-88.

(1980c). A los trabajadores mexicanos. Regeneración, $1^{\circ}$ de julio de 1911, 117-118.

(1980d). Los plebeyos debemos arreglar las cosas. Regeneración, 29 de julio de 1911, 146.

(1980e). El pueblo mexicano es apto para el comunismo. Regeneración, 2 de septiembre de 1911, 171.

(1980f). ¡Muera el orden! Regeneración, 13 de mayo de 1911, 87.

(1981). Artículos Politicos 1912. México:

Ediciones Antorcha.

(1981a). ¿Para qué sirve la autoridad? y otros cuentos. México. Ediciones Antorcha.

(1981b). Expropiación. Regeneración, 16 de diciembre de 1911, 69-72.

. (1981c). Vida Nueva. Regeneración, 13 de noviembre de 1915, 141-150.

(1981d). Buenos medios para conseguir armas. Regeneración, 17 de febrero de 1912, 36.

(1981e). La cuestión social en México. Regeneración, 10 de febrero de 1912, 24.

(1981f). La cuestión social en México. Regeneración, 10 de febrero de 1912, 24-25.

(1982). Artículos Políticos 1914. México: Ediciones Antorcha.

(1982a). No queremos reformas. Regeneración, 13 de junio de 1914, 69.

(1982b). El deber del revolucionario, Regeneración, 13 de junio de 1914, 65.

(2009). Obras de teatro. Oaxaca: CSEIIO.

Gómez, Q. J. (1977). Las ideas politicas de Ricardo Flores Magón. México: Era.
Hernández, P. S. (1984). El magonismo, historia de una pasión libertaria, 1900-1922. México: Era.

Kaplan, S. (2006). Peleamos contra la injusticia. La vida de Enrique Flores Magón contada por él mismo. Oaxaca: IEEPO-SUNEO.

Kropotkin, P. (1902). El apoyo mutuo. Un factor de evolución. Recuperado de http://www.cgtmurcia.org/cultura-libertaria/anarkobiblioteka/pensamiento-libertario/ anarquismo/1047-el-apoyo-mutuo

Editorial Mateu.

(1971). La conquista del pan. Barcelona:

La Botz, D. (2014). American Anarchists and the Mexican Revolution. The American Left and the Mexican Revolution, 1905-1930. Cap. 4. Recuperado de https:// thebasebk.org/wp-content/uploads/2014/05/Chapter-4-American-Anarchists-and-the-Mexican-Revolution.pdf

López, C. y Cortés, O. (1985). El Partido Liberal Mexicano (1906-1908). México: Ediciones Antorcha.

Maldonado, B. (2012). Magonismo y vida comunal mesoamericana. Oaxaca: CSEIIO. Recuperado de https:// anarkobiblioteka2.files.wordpress.com/2016/08/magonismo y vida comunal mesoamericana - benjamc3adn maldonado.pdf

Torres, P. J. (1990). La revolución sin fronteras. México: UNAM.

Zibechi, R. (2008). Autonomías y emancipaciones. América Latina en movimiento. México: Bajo Tierra y Sísifo Ediciones.

\section{Nota del autor:}

Benjamín Maldonado Alvarado

Tutor del Programa de Posgrado de Pedagogía, UNAM. Candidato al Sistema Nacional de Investigadores. benjaoax@yahoo.com.mx 